\title{
Efficacy and Safety of Ghrelin Agonists in Patients with Diabetic Gastroparesis: A Systematic Review and Meta-Analysis
}

\author{
Seung Wook Hong ${ }^{1}$, Jaeyoung Chun ${ }^{1,2}$, Jihye Kim ${ }^{3}$, Jooyoung Lee ${ }^{1}$, Hyun Jung Lee ${ }^{1}$, Hyunsoo Chung ${ }^{1}$, Soo-Jeong Cho ${ }^{1}$, \\ Jong Pil Im ${ }^{1}$, Sang Gyun Kim ${ }^{1}$, and Joo Sung Kim ${ }^{1}$ \\ ${ }^{I}$ Department of Internal Medicine and Liver Research Institute, Seoul National University College of Medicine, ${ }^{2}$ Department of Internal \\ Medicine, Gangnam Severance Hospital, Yonsei University College of Medicine, and ${ }^{3}$ Department of Internal Medicine, CHA Gangnam Medical \\ Center, CHA University School of Medicine, Seoul, Korea
}

Background/Aims: Ghrelin agonists are emerging prokinetic agents for treating gastroparesis. Although recent clinical trials have demonstrated their efficacy in patients with diabetic gastroparesis (DG), the impact of such agents on symptoms and gastric dysmotility remains unclear. We performed a systematic review and meta-analysis to evaluate the efficacy and safety of ghrelin agonists in patients with DG. Methods: A search of common electronic databases (MEDLINE, Embase, and Cochrane Central Register of Controlled Trials) was preformed, using keyword combinations that referenced ghrelin and DG and retrieving all eligible randomized controlled trials (RCTs) of ghrelin agonists versus placebo in patients with DG. The primary outcome measure was the change in patient-reported overall gastroparesis symptom scores. Secondary outcomes included the change in gastric emptying time, specific symptoms related to gastroparesis, and adverse events. A random-effects model was applied to all study outcomes. Heterogeneity among studies was determined by the chi-square test and $\mathrm{I}^{2}$ statistics. Results: We selected six RCTs of patients with DG $(n=557)$ for meta-analysis. Ghrelin agonist administration (vs placebo) significantly improved overall gastroparesis symptoms (standardized mean difference, $-0.34 ; 95 \%$ confidence interval, -0.56 to -0.13 ) and significantly improved symptoms related to gastroparesis, including nausea, vomiting, early satiety, and abdominal pain. Adverse events recorded for ghrelin agonists and placebo did not differ significantly. There was no significant heterogeneity among eligible studies. Conclusions: Compared with placebo, ghrelin agonists are effective and well-tolerated for the treatment of DG. (Gut Liver 2020;14:589-600)
Key Words: Diabetes mellitus; Gastroparesis; Ghrelin; Metaanalysis; Systematic review

\section{INTRODUCTION}

Diabetic gastroparesis (DG) is a serious complication of longstanding diabetes mellitus, resulting in malnutrition, poor glycemic control, and poor quality of life. ${ }^{1,2}$ In a U.S. populationbased study, 10-year cumulative incidences of DG for patients with type 1 and 2 diabetes mellitus were 5.2\% and 1.0\%, respectively; and the risk of DG was $>30$-fold in those with type 1 diabetes mellitus, relative to age-/sex-matched controls. ${ }^{3} \mathrm{Al}-$ though various prokinetic agents, namely dopamine D2 receptor antagonists (metoclopramide and domperidone) and motilin receptor agonists (erythromycin), are current mainstays in the treatment of DG, ${ }^{4,5}$ their long-term use is hampered by adverse events (AEs) (i.e., potential tardive dyskinesia) or waning efficacy due to tachyphylaxis. ${ }^{4}$ Consequently, novel agents with differing mechanisms of action must be developed to ensure long-term efficacy and safety in the treatment of DG.

Ghrelin is a peptide hormone released from gastric mucosal endocrine cells that serves as a ligand for growth hormone secretagogue receptor $1 \mathrm{a}^{6}{ }^{6}$ In vitro studies have shown the expression of ghrelin receptor in enteral nervous system of human and animal intestine. ${ }^{7,8}$ Preclinical studies have shown that ghrelin enhances gastrointestinal (GI) motility via stimulation of vagal signaling, thus prompting efforts at therapeutic targeting. ${ }^{6}$ Ghrelin can also affect GI motility directly within the enteric nerve system or within the central nerve system via crossing the blood-brain barrier. ${ }^{6}$ The prokinetic effects of ghrelin on GI mo-

\footnotetext{
Correspondence to: Jaeyoung Chun

Department of Internal Medicine, Gangnam Severance Hospital, Yonsei University College of Medicine, 211 Eonju-ro, Gangnam-gu, Seoul 06273, Korea

Tel: +82-2-2019-3310, Fax: +82-2-3463-3882, E-mail: j40479@gmail.com

Received on March 28, 2019. Revised on September 20, 2019. Accepted on September 22, 2019. Published online December $11,2019$. pISSN 1976-2283 eISSN 2005-1212 https://doi.org/10.5009/gnl19103

(c) This is an Open Access article distributed under the terms of the Creative Commons Attribution Non-Commercial License (http://creativecommons.org/licenses/by-nc/4.0) which permits unrestricted non-commercial use, distribution, and reproduction in any medium, provided the original work is properly cited.
} 
tility have been demonstrated in postsurgical, opioid-induced as well as diabetic models of rodents with various routes of administration. $^{9}$

Synthetic selective ghrelin receptor agonists, including TZP101 (ulimorelin), TZP-102, and RM-131 (relamorelin), are under development and actually surpass native ghrelin in half-life. ${ }^{10,11}$ TZP-101 is a first-in-class ghrelin agonist with a potent binding affinity for ghrelin receptor. ${ }^{12}$ In the first phase I human study of ghrelin agonists, parenteral TZP-101 was well tolerated with a promising pharmacokinetic and pharmacodynamic profile for use in healthy volunteers. ${ }^{11}$ The volume of distribution is approximately $114 \mathrm{~mL} / \mathrm{kg}$ and half-life values of approximately 13 hours, which were independent of dose. ${ }^{11}$ However, several prospective randomized controlled trials (RCTs) showed inconsistent efficacy of ghrelin agonists for the treatment of DG. ${ }^{13-18}$ In a phase $2 \mathrm{~b}$, randomized, double-blind 12-week placebo-controlled trial, oral TZP-102 was not superior to placebo for the treatment of DG, but there was substantial improvement of symptoms in both ghrelin agonist and placebo groups. ${ }^{15}$ In a recent phase $2 b$ randomized, placebo-controlled trial among the largest number of patients with moderate to severe gastroparesis symptoms related to diabetes, RM-131 significantly reduced gastroparesis symptoms compared to placebo with acceleration of gastric emptying. ${ }^{18}$ Therefore, we conducted this systematic review and meta-analysis to better assess the efficacy and safety of synthetic ghrelin agonists (compared with placebo) in the treatment of DG.

\section{MATERIALS AND METHODS}

This systematic review and meta-analysis were conducted in accord with Preferred Reporting Items for Systematic and Metaanalysis (PRISMA) report guidelines. ${ }^{19}$

\section{Search strategy and study selection}

Using common electronic databases (MEDLINE, Embase, and Cochrane Central Register of Controlled Trials), we searched the medical literature (prior to June 2018) for the following terms: ghrelin AND (diabetic OR diabetes) AND (gastroparesis OR gastropathy). Two independent authors (S.W.H. and J.K.) reviewed and selected pertinent studies, all restricted to English language. Eligible publications met the following criteria: (1) any patient with DG; (2) ghrelin agonist intervention; (3) placebo as comparator; (4) gastroparesis symptoms, gastric emptying time (GET), and AEs as outcomes; and (5) prospective comparative study design (Supplementary Material 1). There were no restrictions on drug regimens or durations of treatment. Abstracts, case reports, review articles, non-comparative studies, and preclinical studies were excluded from this meta-analysis.

\section{Data extraction and quality assessment}

Two authors (S.W.H. and J.K.) independently extracted data from eligible studies, resolving any disagreement by consensus. Extracted data included the following: named author(s); trial location; year of publication; drug regimen and duration of treat-
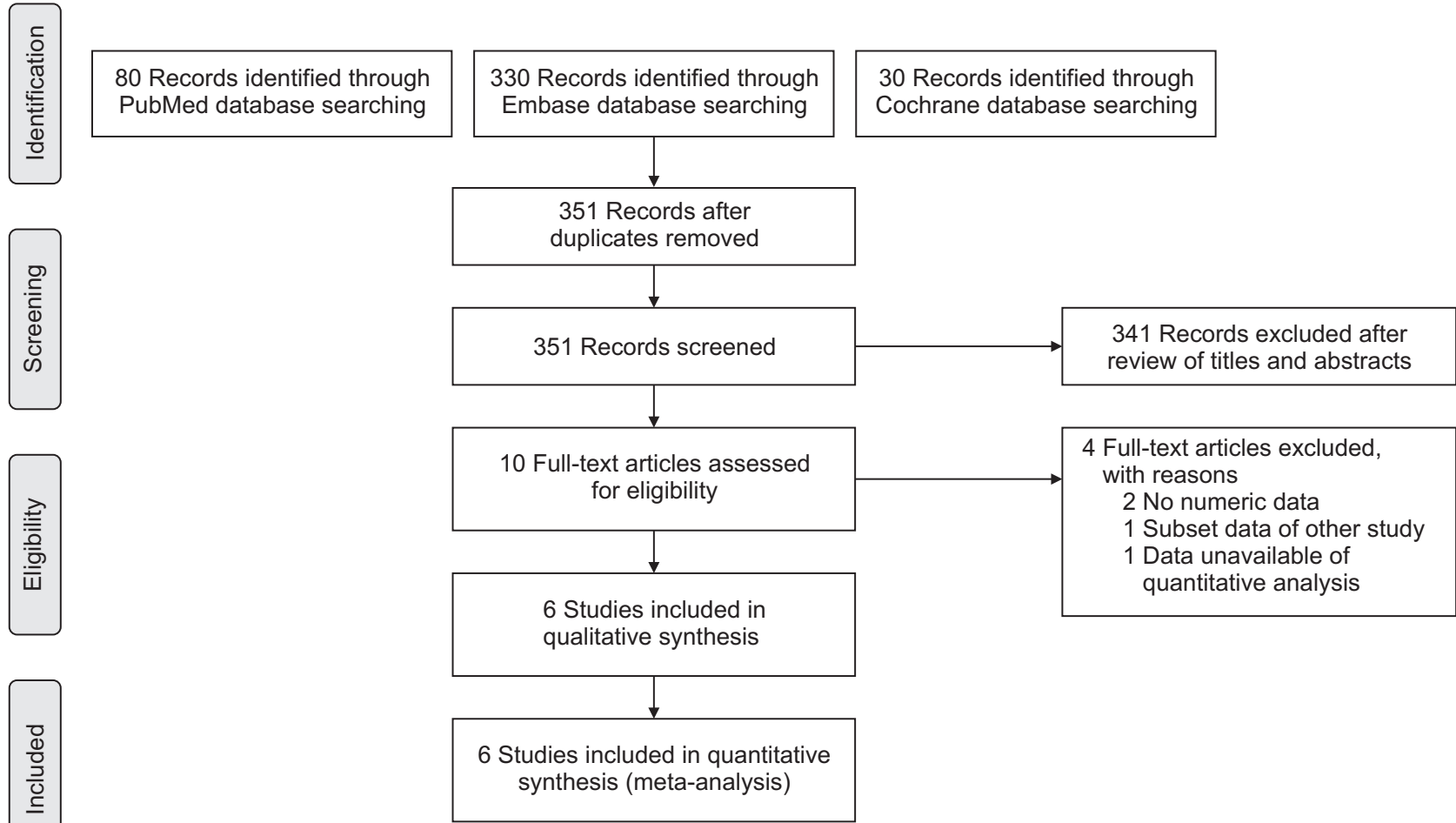

Fig. 1. Flowchart of meta-analysis study selection. 
ment; number of enrollees in each treatment arm; posttreatment change in DG symptom scores and scale applied in symptom assessment; change in GET and method of measurement; and AEs. In dose-dependent RCTs, the regimen with the greatest clinical efficacy in terms of the change in overall gastroparesis symptoms was preferred for extracting data (Supplementary Table 1). In studies with varying assessment scales, data related to primary outcome measures were chiefly extracted. We also contacted corresponding authors to clarify or remedy confusing or missing information. The risk of bias tool of the Cochrane Group served to gauge quality of analysis. ${ }^{20}$

\section{Study outcomes and measurement scales}

The primary outcome measure was change in severity of overall gastroparesis symptoms, based on patient-reported scales. Secondary outcomes were change in GET, specific gastroparesis-related symptoms gauged before and after treatment, and AEs. There are a variety of patient-reported scales for measuring symptoms related to gastroparesis. The Gastroparesis Cardinal Symptom Index (GCSI) ${ }^{21}$ and Patient Assessment of Upper Gastrointestinal Symptom Severity Index (PAGI-SYM) have been widely used. ${ }^{22}$ Recently, GCSI was revised as a daily diary, ${ }^{23}$ and the Diabetic Gastroparesis Symptom Severity Diary (DGSSD) was also developed to score symptoms of DG. In this regard, we made no restrictions on patient-reported scales when selecting study outcomes for meta-analysis. GET was equated with gastric emptying half-time after ingesting an isotope-labeled diet. A breath test or scintigraphy served to measure halftimes of gastric emptying. Data on GET were likewise extracted without regard to measurement methods. We also extracted data on AEs and serious adverse events (SAEs), based on results presented in each study, detailing events and numbers of patients affected.

\section{Statistical methods}

Dichotomous outcomes were calculated as odds ratios (ORs), with 95\% confidence intervals (CIs). Continuous data were each expressed as standardized mean difference (SMD) or mean difference (MD), with 95\% CI. Given the diversity in scoring of gastroparesis symptoms, we used SMD to report pooled treatment effects, whereas results of same-scale GET analytics were expressed as MDs. A random-effects model was ultimately invoked, applying inverse-variance method for all study outcomes. Some data proved insufficient to calculate standard deviations of changes occurring, so we imputed values (correlation coefficients) derived from other studies. ${ }^{20} \mathrm{~A} p<0.05$ was considered statistically significant. Heterogeneity among studies was estimated via chi-square test and $\mathrm{I}^{2}$ statistics. Significance in chi-square testing was set at $\mathrm{p}<0.10$, gauging heterogeneity among studies by $\mathrm{I}^{2}$ statistics as follows: 0\% to 40\%, marginal; $30 \%$ to $60 \%$, moderate; $50 \%$ to $90 \%$, substantial; and $75 \%$ to $100 \%$, immense. We assessed potential causes of substantial

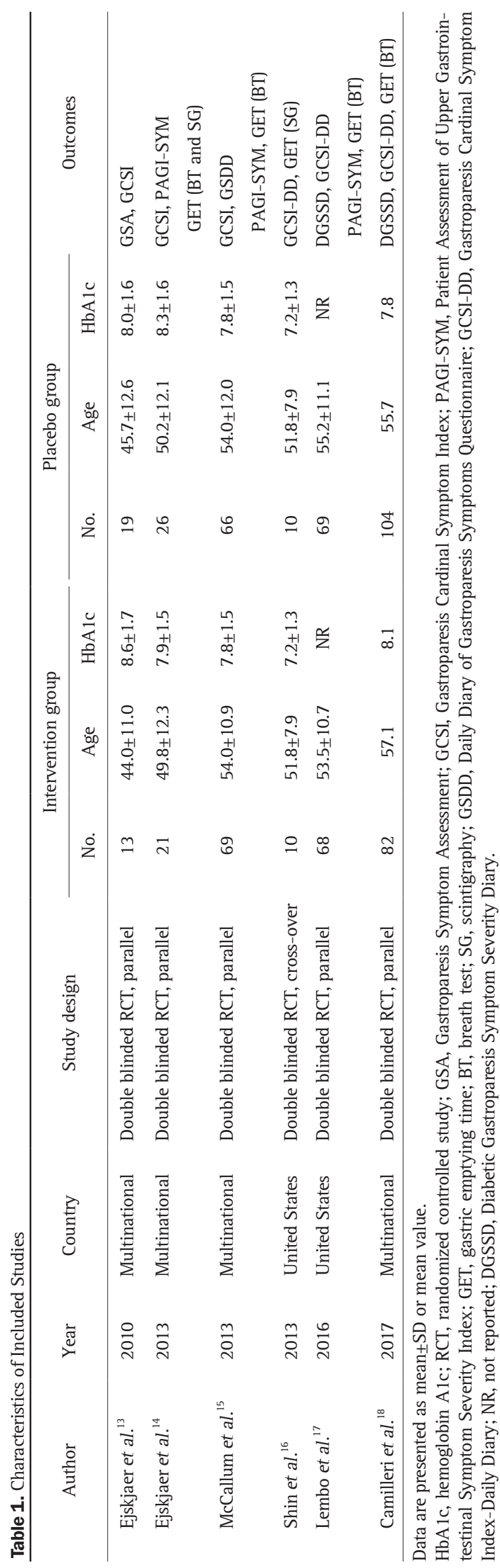


Table 2. Regimen and Treatment Duration of Ghrelin Agonists in Each Study

\begin{tabular}{|c|c|c|c|c|}
\hline Author & Medication name & Regimen & Selected regimen for analysis & Treatment duration \\
\hline Ejskjaer et al. ${ }^{13}$ & TPZ-101* & $\begin{array}{l}\text { 20, 40, } 80160,320 \text {, and } 600 \mu \mathrm{g} / \mathrm{kg} \\
\text { single daily IV infusion }\end{array}$ & $\begin{array}{r}80 \mu \mathrm{g} / \mathrm{kg} \text { single } \\
\text { daily infusion }\end{array}$ & 4 Days \\
\hline Ejskjaer et al. ${ }^{14}$ & TPZ-102 & 10, 20, and $40 \mathrm{mg}$ qd p.o. & 20 mg qd p.o. & 28 Days \\
\hline McCallum et al. ${ }^{15}$ & TPZ-102 & 10, 20 mg qd p.o., 10 mg tid p.o. & 10 mg qd p.o. & 12 Weeks \\
\hline Shin et al. ${ }^{16}$ & $\mathrm{RM}-131^{\dagger}$ & $100 \mu \mathrm{g}$ qd s.c. & $100 \mu \mathrm{g}$ qd s.c. & 1 Days \\
\hline Lembo et al. ${ }^{17}$ & RM-131 & $10 \mu \mathrm{g}$ qd, bid s.c. & $10 \mu \mathrm{g}$ bid s.c. & 28 Days \\
\hline Camilleri et al. ${ }^{18}$ & RM-131 & 10,30 , and $100 \mu \mathrm{g}$ bid s.c. & $100 \mu \mathrm{g}$ bid s.c. & 12 Weeks \\
\hline
\end{tabular}

IV, intravenous; qd, once daily; p.o., per oral; tid, three times daily; s.c., subcutaneous; bid, twice daily.

*TPZ101 referred to as ulimorelin; ${ }^{\dagger} \mathrm{RM}-131$ referred to as relamorelin.

A Type of drug

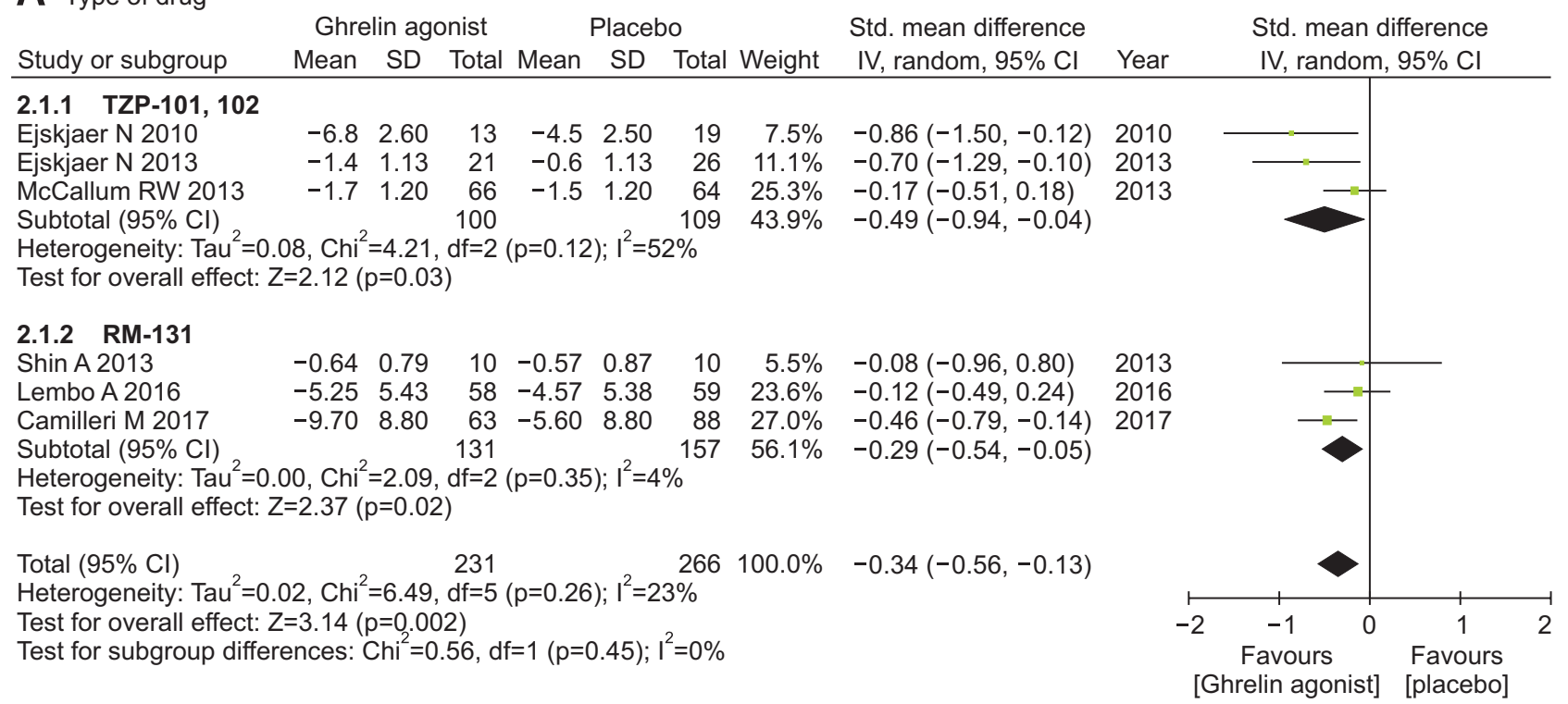

\section{B Administration route}

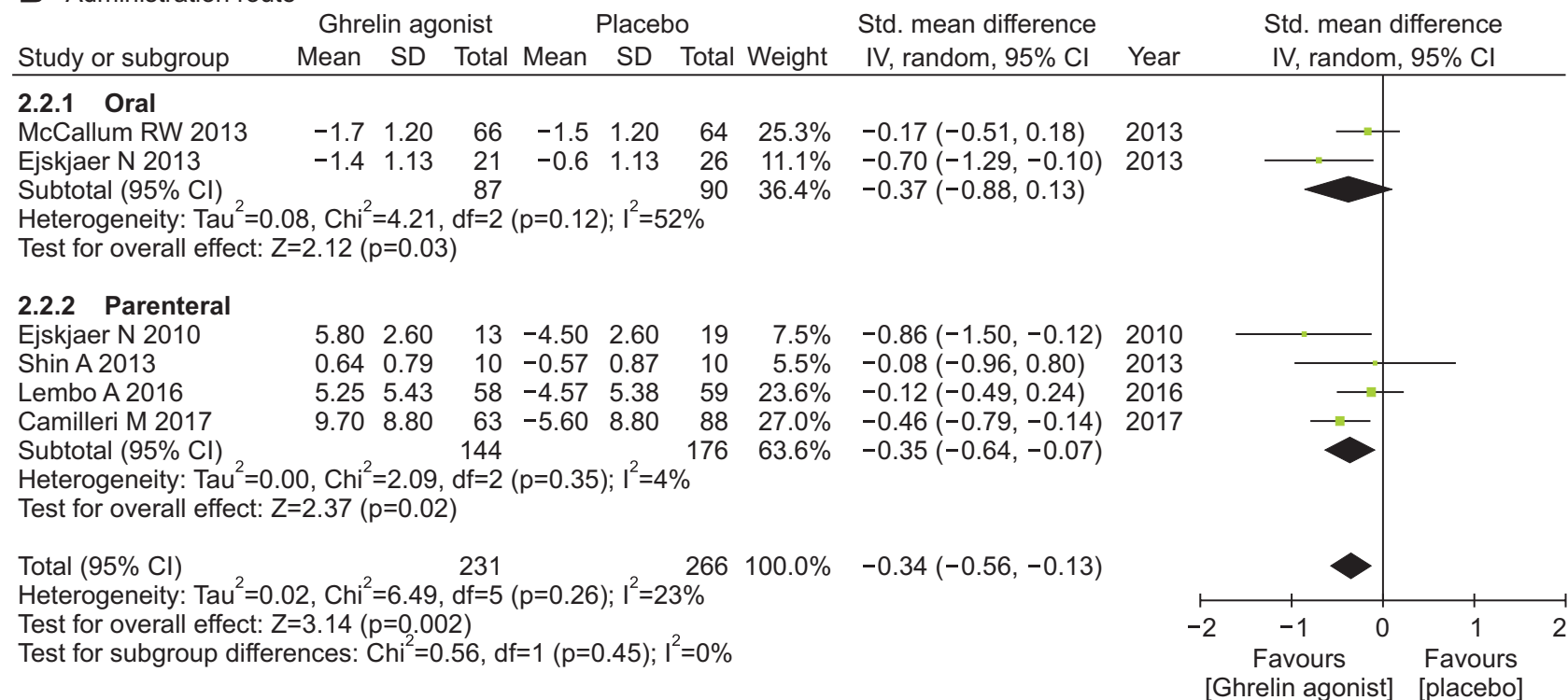

Fig. 2. Efficacy of ghrelin agonists (vs placebo) for treating gastroparesis symptoms overall: (A) subgroup analysis by agent (TZP-101, 102, or RM131), (B) subgroup analysis by route of administration (parenteral vs oral), and (C) subgroup analysis by treatment duration.

Std., standardized; IV, inverse variance; CI, confidence interval. 
C Treatment duration

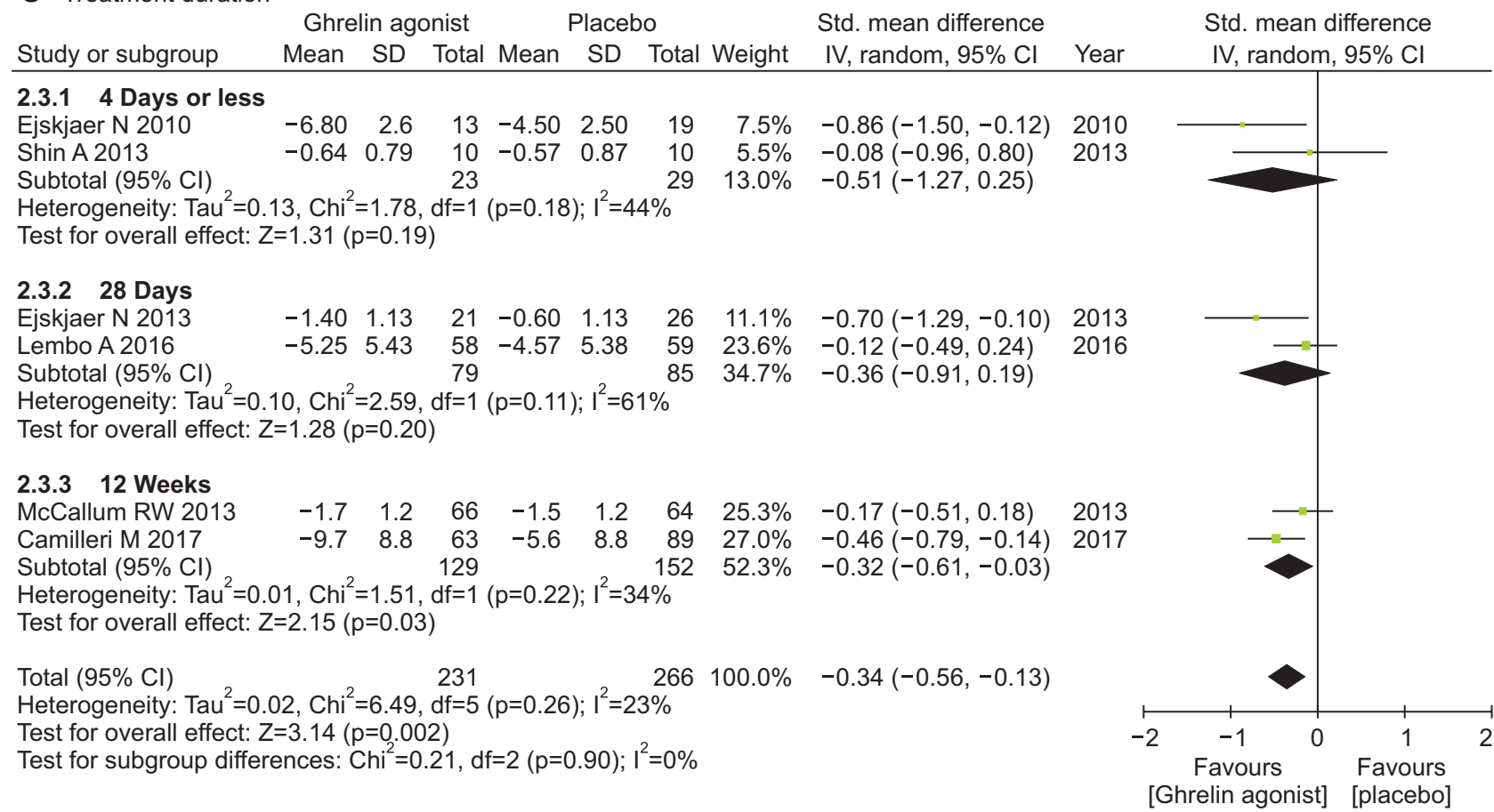

Fig. 2. Continued.

heterogeneity and conducted subgroup analyses according to type of ghrelin agonists, route of administration and treatment duration. All computations relied on Review Manager freeware (RevMan v5.3; Cochrane Community, London, UK).

\section{RESULTS}

\section{Search selection}

Our literature search returned a total of 438 articles. Discounting duplicates, 351 articles remained for title and abstract screening. The latter yielded 10 articles for full text assessment, but only six met our inclusion criteria and advanced to data extraction/synthesis (Fig. 1). ${ }^{13-18}$ A study by Shin et al. ${ }^{24}$ fulfilled the conditions for enrollment in this meta-analysis, but the values were only presented with median and interquartile range. The values with median and interquartile range could not be converted to those with mean and standard deviation in the absence of raw data. Hence, the study was excluded from the qualitative synthesis stage.

\section{Study characteristics and risk of bias assessment}

All publications selected for analysis $(n=557)$ were prospective RCTs. Each subject with DG had been stratified to test agent $(n=263)$ or placebo $(n=294)$ groups. Five studies were parallel investigations, ${ }^{13-15,17,18}$ and the remaining trial was a cross-over study.$^{16}$ Four were multinational efforts, ${ }^{13-15,18}$ and two were conducted in the United States. ${ }^{16,17}$ Patient-reported scales for assessment of gastroparesis symptoms were distributed as fol- lows: GCSI, three RCTs $;{ }^{13-15}$ GCSI daily diary, four RCTs $;{ }^{15-18}$ PAGI-SYM, three RCTs; $;^{14,15,17}$ and DGSSD, two RCTs (Table 1). ${ }^{17,18}$ In all study populations, prolongation of GET was stipulated in screening phases of those studies eligible for meta-analysis, five of them designating change in GET as a study outcome. ${ }^{14-18}$ With exception of one RCT (using scintigraphy), GET was determined by breath test. ${ }^{16}$ Characteristics and study outcomes of RCTs selected for meta-analysis are summarized in Table 1.

These studies differed in terms of drugs used, dosages, methods of administration, and treatment durations (Table 2). One study was aimed at TZP-101, ${ }^{13}$ another two tested TZP-102, ${ }^{14,15}$ and the final three evaluated RM-131, ${ }^{16-18}$ showing wide variation in duration of treatment (range, 1 day to 12 weeks). The report of McCallum et al. ${ }^{15}$ provided results of two clinical trials with different dosing schedules (once daily and three times daily). Because the researchers allowed dual enrollment, we selected one of the regimens by the selection criteria according to the greatest clinical efficacy on overall gastroparesis symptoms. ${ }^{15}$

The risk of bias is shown in Supplementary Figs 1 and 2 . Methods of randomization and allocation concealment were clearly detailed in all studies having low risks of performance and detection bias, except the study by Lembo et al. ${ }^{17}$ with insufficient information on the risk of allocation concealment. Attrition rates in two RCTs were high. ${ }^{17,18}$

\section{Overall gastroparesis symptoms}

Our meta-analysis confirmed a significantly better performance by ghrelin agonists (vs placebo) regarding change in 
594 Gut and Liver, Vol. 14, No. 5, September 2020

A Nausea

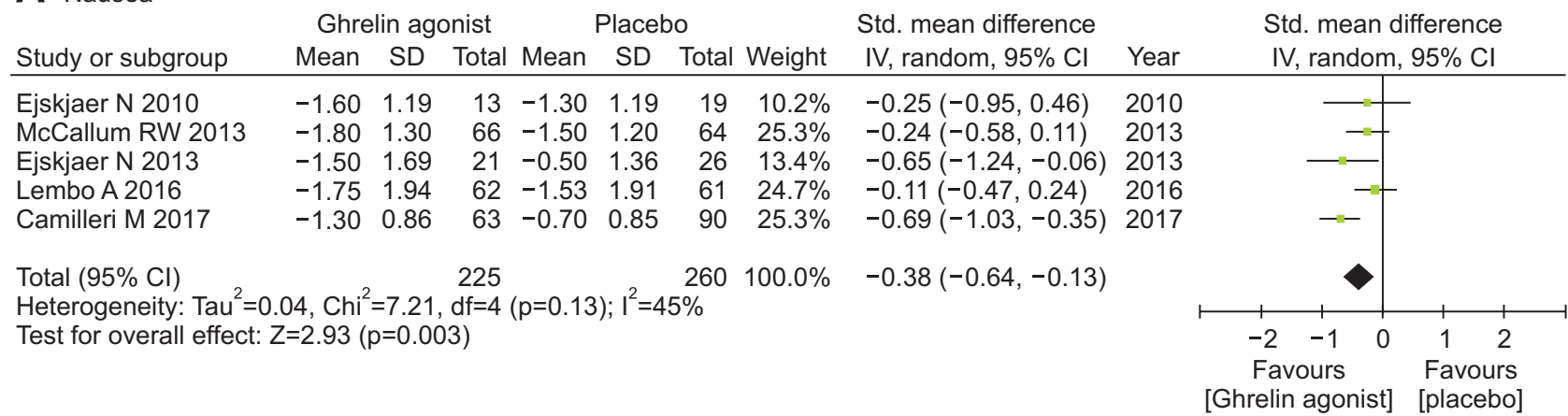

B Vomiting

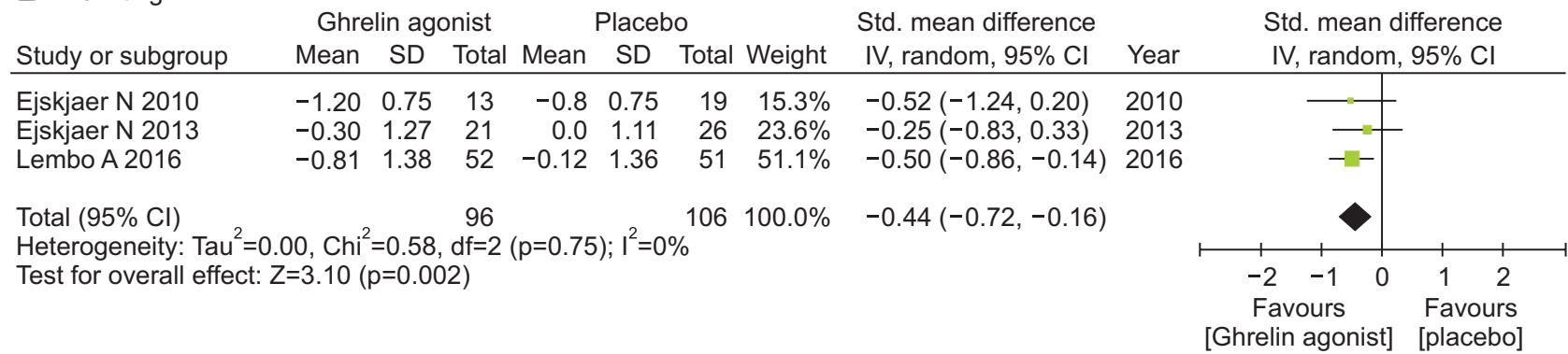

C Early satiety

Ghrelin agonist Placebo Std. mean difference

Study or subgroup Mean SD Total Mean SD Total Weight IV, random, $95 \% \mathrm{Cl}$ Year

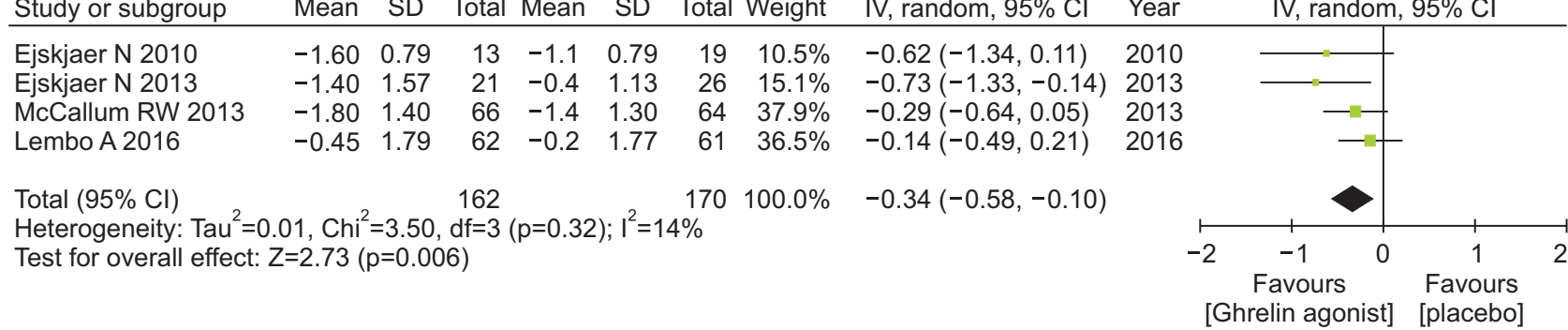

D Bloating

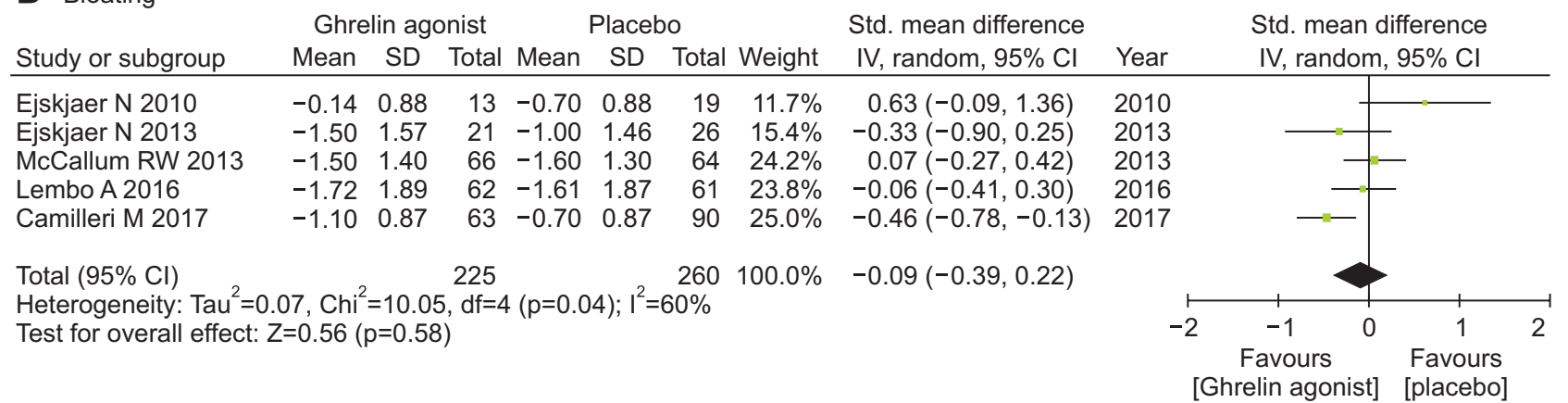

Fig. 3. Efficacies of ghrelin agonists (vs placebo) in treating specific gastroparesis symptoms: (A) nausea, (B) vomiting, (C) early satiety, (D) bloating, and (E) abdominal pain.

Std., standardized; IV, inverse variance; CI, confidence interval.

overall gastroparesis symptoms scores (SMD, -0.34; 95\% CI, -0.56 to -0.13$)$. There was no significant heterogeneity among studies ( $\mathrm{p}=0.26 ; I^{2}=23 \%$ ). RM-131 differed significantly, compared with placebo (SMD, -0.29 ; 95\% CI, -0.54 to -0.05 ), and so did TZP-101,102 (SMD, -0.49; 95\% CI, -0.94 to -0.04). Ghrelin agonist via parenteral route differed significantly, compared with placebo (SMD, -0.35 ; 95\% CI, -0.64 to -0.07 ), although orally administered ghrelin agonist did not (SMD, -0.37; 95\% CI, -0.88 to 0.13 ). The efficacy of ghrelin agonists for improving overall gastroparesis symptoms was only found at 12-week treatment duration (Fig. 2). 
Abdominal pain

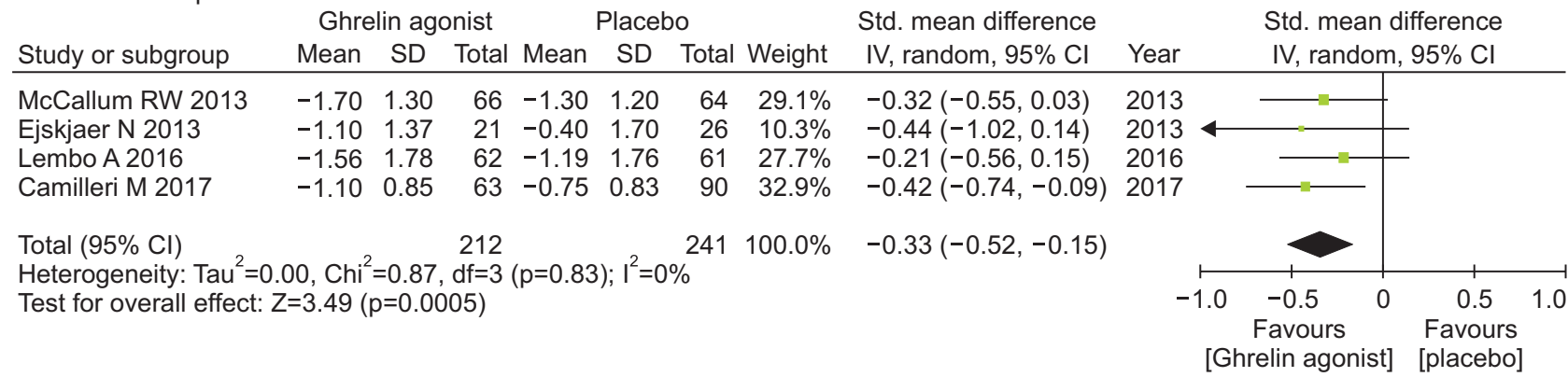

Fig. 3. Continued.

\begin{tabular}{|c|c|c|c|c|c|c|c|c|c|c|c|}
\hline Study or subgroup & \multicolumn{3}{|c|}{ Ghrelin agonist } & \multicolumn{3}{|c|}{ Placebo } & \multicolumn{3}{|c|}{ Mean difference } & \multicolumn{2}{|c|}{$\begin{array}{l}\text { Mean difference } \\
\text { IV, random, } 95 \% \mathrm{Cl}\end{array}$} \\
\hline \multicolumn{12}{|c|}{ 4.1.1 TZP-102 (oral) } \\
\hline Ejskjaer N 2013 & -18.9 & 41.7 & 21 & -24.8 & 46.0 & 26 & $11.1 \%$ & $5.90(-19.21,31.01)$ & 2013 & & \\
\hline McCallum RW 2013 & -5.0 & 39.0 & 66 & -5.0 & 37.0 & 64 & $28.9 \%$ & $0.00(-13.07,13.07)$ & 2013 & & \\
\hline Subtotal $(95 \% \mathrm{Cl})$ & & & 87 & & & 90 & $40.0 \%$ & $1.26(-10.33,12.85)$ & & & \\
\hline \multicolumn{12}{|c|}{$\begin{array}{l}\text { Heterogeneity: Tau }{ }^{2}=0.00 ; \mathrm{Chi}^{2}=0.17, \mathrm{df}=1(p=0.68) ;\left.\right|^{2}=0 \% \\
\text { Test for overall effect: } Z=0.21(p=0.83)\end{array}$} \\
\hline \multicolumn{12}{|c|}{ 4.1.2 RM-131 (parenteral) } \\
\hline Lembo A 2016 & -22.9 & 34.93 & 59 & -7.5 & 34.93 & & $30.4 \%$ & $-15.40(-27.90,-2.90)$ & 2016 & & \\
\hline Camilleri M 2017 & -13.6 & 40.50 & 63 & & 38.50 & 88 & $29.5 \%$ & $-13.60(-26.43,-0.77)$ & 2017 & & \\
\hline \multirow{2}{*}{\multicolumn{12}{|c|}{$\begin{array}{l}\text { Heterogeneity: Tau }{ }^{2}=0.00 ; \mathrm{Chi}^{2}=0.04, \mathrm{df}=1(p=0.84) ; I^{2}=0 \% \\
\text { Test for overall effect: } Z=3.18(p=0.001)\end{array}$}} \\
\hline & & & & & & & & & & & \\
\hline \multicolumn{12}{|c|}{$\begin{array}{l}\text { Total }(95 \% \mathrm{Cl}) \\
\text { Heterogeneity: } \mathrm{Tau}^{2}=30.61 ; \mathrm{Chi}^{2}=4.46, \mathrm{df}=3(\mathrm{p}=0.20) ; \mathrm{I}^{2}=36 \%\end{array}$} \\
\hline \multicolumn{10}{|c|}{$\begin{array}{l}\text { Test for overall effect: } Z=1.73(p=0.08) \\
\text { Test for subgroup differences: } \mathrm{Chi}^{2}=4.46, \mathrm{df}=1(p=0.03) ; \mathrm{I}^{2}=77.6 \%\end{array}$} & $\begin{array}{c}-20-10 \quad 0 \\
\text { Favours } \\
\text { [ghrelin agonist] }\end{array}$ & $\begin{array}{c}1020 \\
\text { Favours } \\
\text { [placebo] }\end{array}$ \\
\hline
\end{tabular}

Fig. 4. Effects of ghrelin agonists (vs placebo) on gastric emptying time. $\mathrm{IV}$, inverse variance; CI, confidence interval.

\section{Specific gastroparesis symptoms}

Ghrelin agonists (vs placebo) significantly improved nausea (SMD, -0.38 ; 95\% CI, -0.64 to -0.13 ), vomiting (SMD, -0.44 ; $95 \%$ CI, -0.72 to -0.16 ), early satiety (SMD, $-0.34 ; 95 \%$ CI, -0.58 to -0.10 ) and abdominal pain (SMD, -0.33 ; 95\% CI, -0.52 to -0.15). However, bloating was not improved by ghrelin agonist (i.e., similar to placebo) (Fig. 3).

\section{Gastric emptying time}

In a study by Shin et al., ${ }^{16}$ there were no available data on GET at baseline, even upon contacting authors for information. This study was subsequently excluded from meta-analysis. Ghrelin agonists showed a tendency to improve GET compared with placebo (MD, -8.04 ; 95\% CI, -17.17 to 1.08). RM-131 (parenteral) significantly shortened GET, compared with placebo (MD, -14:52; 95\% CI, -23.48 to -5.57 ), but TZP-102 (oral) did not (Fig. 4).

\section{Adverse events}

The pooled effects of AEs were based on the number of patients with AEs in all eligible studies, regardless of dosing regimen. The proportion of patients with AEs or SAEs in each study and the relevance to treatment were summarized in Table 3. Accordingly, no significant difference between ghrelin agonist and placebo was evident (OR, 1.33; 95\% CI, 0.71 to 2.48). Similarly, there was no significant difference in pooled SAEs (OR, 1.00; 95\% CI, 0.54 to 1.83) (Fig. 5). AEs common to each ghrelin agonist were GI symptoms, such as nausea, vomiting, diarrhea, and abdominal pain. AEs related to glycemic control were also frequently reported. SAEs were rare, including coronary heart disease, atrial fibrillation, diabetic ketoacidosis, and serious infectious (i.e., pneumonia, urinary tract infection, and sepsis). Most studies under investigation did not clearly document associations between ghrelin agonists and AEs, and no definitive doseresponse relations were discerned. Although AEs linked to hyperglycemia were not significantly increased, blood glucose trended higher in the ghrelin agonist group (Supplementary Fig. 3). In a 


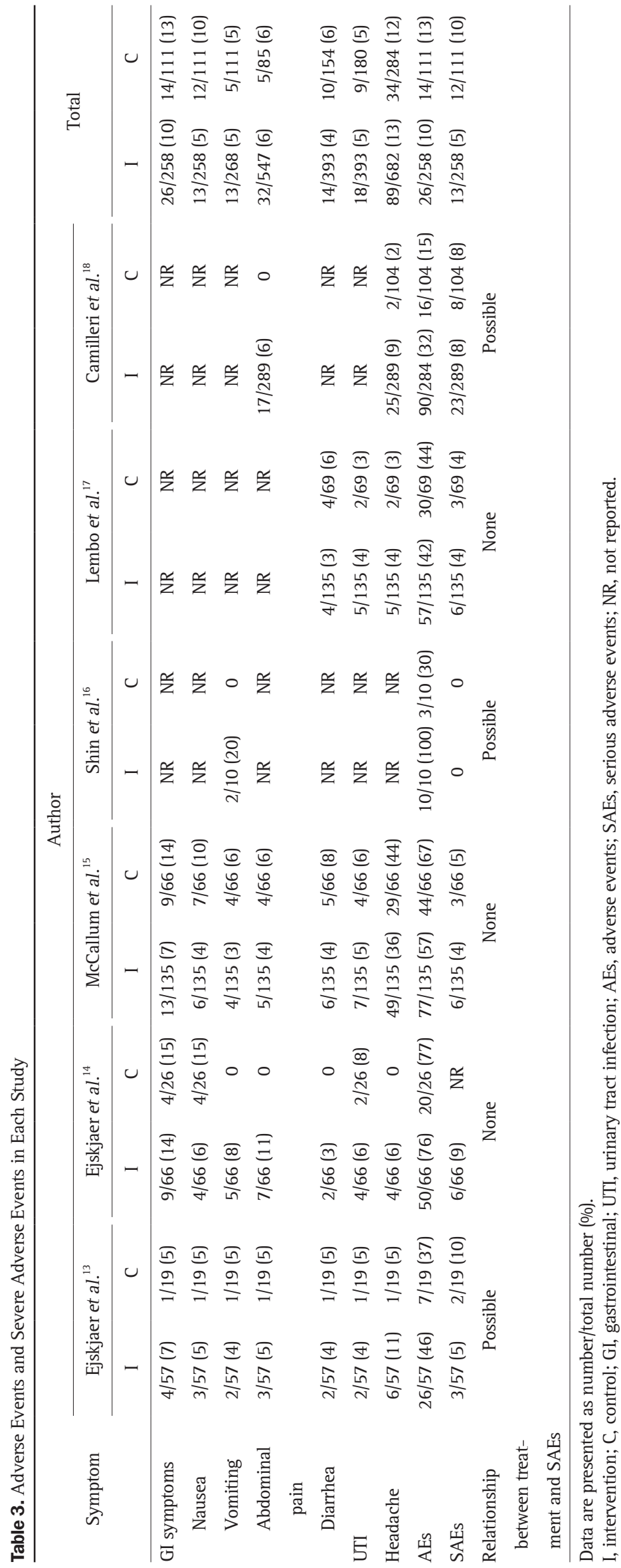


A AEs

\begin{tabular}{l} 
Study or subgroup \\
\hline Ejskjaer N 2010 \\
Ejskjaer N 2013 \\
McCallum RW 2013 \\
Shin A 2013 \\
Lembo A 2016 \\
Camilleri M 2017
\end{tabular}

Ghrelin agonist Placebo

Odds ratio

Odds ratio

Events Total Events Total Weight IV, random, 95\% Cl Year IV, random, $95 \% \mathrm{Cl}$

Total events

$\begin{array}{lllll}26 & 57 & 7 & 19 & 15.2 \%\end{array}$

$1.44(0.49,4.18)$

2010

$\begin{array}{lllll}50 & 66 & 20 & 26 & 15.2 \%\end{array}$

$0.94(0.32,2.74)$

$0.66(0.36,1.23)$

2013

$\begin{array}{lllll}77 & 135 & 44 & 66 & 21.8 \%\end{array}$

$10 \quad 10$

$3 \quad 10 \quad 3.5 \%$

. $00(2.01,1006.75) 2013$

$0.95(0.53,1.71)$

2013

$90 \quad 284$

$2.55(1.42,4.60)$

2017

$1.33(0.71,2.48)$

Heterogeneity: Tau $^{2}=0.37 ; \mathrm{Chi}^{2}=16.00, \mathrm{df}=5(\mathrm{p}=0.007) ; \mathrm{I}^{2}=69 \%$

Test for overall effect: $Z=0.90(p=0.37)$

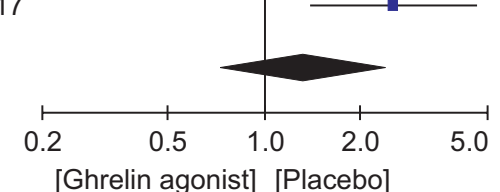

\section{B SAES}

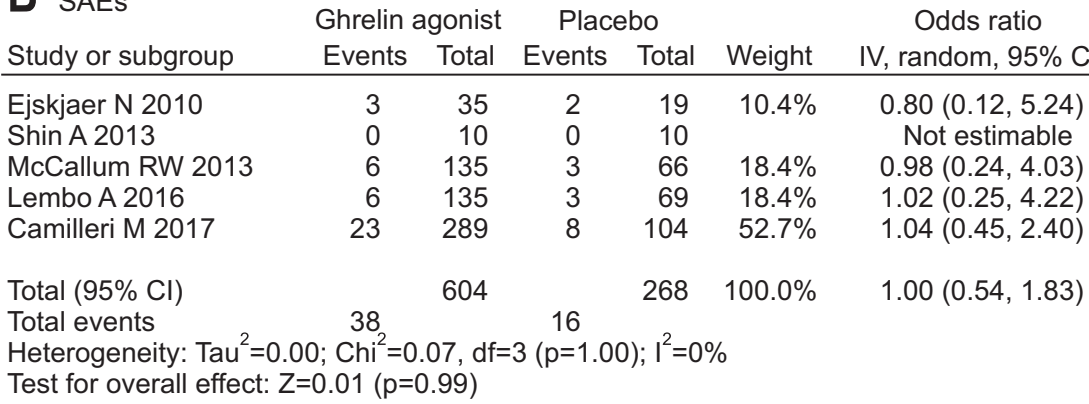

Fig. 5. Ghrelin agonist and placebo group comparison: (A) adverse events and (B) serious adverse events. $\mathrm{IV}$, inverse variance; CI, confidence interval.

study by Camilleri et al., ${ }^{18}$ some recipients of RM-131 displayed dose-dependent glycemic increases.

\section{DISCUSSION}

This meta-analysis is seemingly the first to evaluate the efficacy and safety of ghrelin agonists (vs placebo) in the treatment of DG. We found that such agents significantly improve overall gastroparesis symptoms and show a tendency to reduce GET. Although the relation between symptom improvement and GET is still controversial, both parameters are current standard outcome measures of drugs used to treat gastroparesis. ${ }^{25}$ Hence, our data support the therapeutic potential of ghrelin agonists in managing patients with DG.

Although all types of ghrelin agonists significantly outperformed placebo in patients with DG in terms of improving overall DG symptoms, there was a significant difference of the effects on GET between parenteral RM-131 and oral TZP-102. Preclinical data on RM-131 indicates a much greater potency (600- to 1,800-fold) for ghrelin receptors than TZP-102, offering a plausible explanation for the differing efficacy observed in patients with DG. ${ }^{10}$ Among the 3 studies using RM-131 on the treatment of patients with DG, only study by Camilleri et al. ${ }^{18}$ reported the significant efficacy of RM-131 on improvement of overall gastroparesis symptoms following the long-term administration of the highest dose (100 $\mu \mathrm{g}$ twice daily for 12 weeks), compared to placebo. Therefore, various dosage and treatment duration of RM-131 may affect the inconsistent results among the studies. However, the route of administration might also be related to the efficacy of ghrelin agonists. Compared with oral TZP-102 intake for more than 4 weeks, short-term parenteral administration of TZP-101 brought significantly greater improvement in overall symptoms. Unfortunately, there is no published data as yet on the bioavailability of orally administered ghrelin agonists, and our preliminary evidence is inconclusive. As further validation, oral formulations of ghrelin agonists more potent than TZP-102 must be evaluated in patients with DG.

In terms of specific DG-related GI symptoms, ghrelin agonists significantly improved abdominal pain, nausea, early satiety and vomiting, but not bloating. Although the pathophysiology of symptoms related to DG remains elusive, ${ }^{26}$ various sources maintain that chief etiologic factors of given GI symptoms may differ as follows: (1) visceral hypersensitivity to gastric distension leads to epigastric pain; (2) delayed gastric emptying results in postprandial fullness, nausea, and vomiting; and (3) impaired accommodation promotes early satiety. ${ }^{27-30}$ Thus, the differing efficacies displayed in these trials for each symptom of DG are explainable. To date, the major role defined for ghrelin agonists is an enhancement of GI motility via vagal stimulation. ${ }^{6}$ The ghrelin infusion reduced gastric accommodation in the clinical trial for healthy volunteers and at least one preclinical study suggests that ghrelin has antinociceptive effects, which counter 
visceral hypersensitivity. ${ }^{31,32}$ Indeed, ghrelin agonists act to reduce GET, visceral hypersensitivity and gastric accommodation, thereby improving nausea, vomiting, early satiety, and abdominal pain. On the other hand, bloating may be a heterogeneous condition involving multiple pathophysiologic factors. ${ }^{33}$ Consequently ghrelin agonists may offer no benefits for bloating related to DG.

One of the major concerns when using ghrelin agonists is the adverse effect on glycemic control. Tight glycemic control is paramount in patients with DG, so it is essential to address this issue. $^{4}$ Earlier efforts have shown that the infusion of ghrelin agonists increases plasma growth hormone concentration, thus opposing the action of insulin. ${ }^{34,35}$ In a literature review, however, strong evidence of significant blood glucose elevations due to ghrelin agonists was lacking in patients with DG. ${ }^{24,34-36}$ Herein, the risk of AEs related to hyperglycemia only trended higher in our ghrelin agonist group, failing to dispel such fears. Additional prospective studies are needed to clarify this aspect of long-term ghrelin agonist use and other related complications.

This study has several acknowledged limitations. Although significant improvement was shown at the 12-week treatment duration, the efficacy of ghrelin agonists for improving overall gastroparesis symptoms could not be fully evaluated based on treatment duration due to lack of studies enrolled in this metaanalysis. The long-term efficacy of ghrelin agonists in managing DG could not be ascertained as well, because the maximum study period among studies included was a mere 12 weeks. In addition, there was no data on the enduring efficacy of these agents after their withdrawal. Another weakness is that the rare AEs of ghrelin agonists in the setting of DG could not be properly assessed in the small number of available patients. There is concern that ghrelin agonist may heighten cancer risks due to the carcinogenic effects of growth hormone. ${ }^{37}$ Although in vivo study findings indicate that serum ghrelin level has a null or inverse association with cancer risks, ${ }^{38}$ the role of ghrelin/ ghrelin agonists in the development and progression of cancer is still in doubt. Ultimately, large-scale clinical studies will be needed to evaluate the long-term efficacy and safety profile of ghrelin agonists during treatment of DG. Finally, it remains elusive whether the inconsistent results regarding the efficacy of ghrelin agonists on overall symptoms related to DG were due to administration route or dosage. The efficacy of ghrelin agonists for the treatment of DG may be valid only for specific regimen although overall efficacy of ghrelin agonists for improvement of gastroparesis symptoms in the meta-analysis. Further studies are required to determine oral bioavailability and comparative efficacy of ghrelin agonists between drug types in patients with DG.

In conclusion, ghrelin agonists effectively improve symptoms related to gastroparesis in patients with DG, more so than placebo. Despite concerns over blood glucose levels during long-

term ghrelin agonist use, no significant treatment-related safety issues emerged in the course of this meta-analysis.

\section{CONFLICTS OF INTEREST}

No potential conflict of interest relevant to this article was reported.

\section{ACKNOWLEDGEMENTS}

The authors wish to thank Myoung-jin Jang, the Medical Research Collaborating Center, and Seoul National University Hospital for their assistance with statistical aspects of this metaanalysis.

\section{AUTHOR CONTRIBUTIONS}

Literature search and data extraction: S.W.H., J.K. Statistical analysis: S.W.H., H.J.L. Manuscript draft: S.W.H., J.L., J.C. Critical review: S.J.C., H.C., J.P.I. Contribution to discussion: J.C. S.G.K., J.S.K

\section{ORCID}

Seung Wook Hong

Jaeyoung Chun

Jihye Kim

Jooyoung Lee

Hyun Jung Lee

Hyunsoo Chung

Soo-Jeong Cho

Jong Pil Im

Sang Gyun Kim

Joo Sung Kim https://orcid.org/0000-0003-1440-9950
https://orcid.org/0000-0002-4212-0380
https://orcid.org/0000-0003-0763-2935
https://orcid.org/0000-0003-1652-088X
https://orcid.org/0000-0003-2764-9339
https://orcid.org/0000-0001-5159-357X
https://orcid.org/0000-0001-7144-0589
https://orcid.org/0000-0003-1584-0160
https://orcid.org/0000-0003-1799-9028
https://orcid.org/0000-0001-6835-4735

\section{REFERENCES}

1. Camilleri M, Bharucha AE, Farrugia G. Epidemiology, mechanisms, and management of diabetic gastroparesis. Clin Gastroenterol Hepatol 2011;9:5-12.

2. Liu N, Abell T. Gastroparesis updates on pathogenesis and management. Gut Liver 2017;11:579-589.

3. Choung RS, Locke GR 3rd, Schleck CD, Zinsmeister AR, Melton LJ 3rd, Talley NJ. Risk of gastroparesis in subjects with type 1 and 2 diabetes in the general population. Am J Gastroenterol 2012;107:82-88.

4. Camilleri M, Parkman HP, Shafi MA, Abell TL, Gerson L; American College of Gastroenterology. Clinical guideline: management of gastroparesis. Am J Gastroenterol 2013;108:18-37.

5. Kumar M, Chapman A, Javed S, Alam U, Malik RA, Azmi S. The investigation and treatment of diabetic gastroparesis. Clin Ther 2018;40:850-861. 
6. Camilleri M, Papathanasopoulos A, Odunsi ST. Actions and therapeutic pathways of ghrelin for gastrointestinal disorders. Nat Rev Gastroenterol Hepatol 2009;6:343-352.

7. Dass NB, Munonyara M, Bassil AK, et al. Growth hormone secretagogue receptors in rat and human gastrointestinal tract and the effects of ghrelin. Neuroscience 2003;120:443-453.

8. Xu L, Depoortere I, Tomasetto C, et al. Evidence for the presence of motilin, ghrelin, and the motilin and ghrelin receptor in neurons of the myenteric plexus. Regul Pept 2005;124:119-125.

9. Avau B, Carbone F, Tack J, Depoortere I. Ghrelin signaling in the gut, its physiological properties, and therapeutic potential. Neurogastroenterol Motil 2013;25:720-732.

10. Van der Ploeg L, Laken H, Sharma S, et al. Preclinical gastrointestinal prokinetic efficacy and endocrine effects of the ghrelin mimetic RM-131. Life Sci 2014;109:20-29.

11. Lasseter KC, Shaughnessy L, Cummings D, et al. Ghrelin agonist (TZP-101): safety, pharmacokinetics and pharmacodynamic evaluation in healthy volunteers: a phase I, first-in-human study. J Clin Pharmacol 2008;48:193-202.

12. Fraser GL, Hoveyda HR, Tannenbaum GS. Pharmacological demarcation of the growth hormone, gut motility and feeding effects of ghrelin using a novel ghrelin receptor agonist. Endocrinology 2008;149:6280-6288.

13. Ejskjaer N, Dimcevski G, Wo J, et al. Safety and efficacy of ghrelin agonist TZP-101 in relieving symptoms in patients with diabetic gastroparesis: a randomized, placebo-controlled study. Neurogastroenterol Motil 2010;22:e1069-e1281.

14. Ejskjaer N, Wo JM, Esfandyari T, et al. A phase 2a, randomized, double-blind 28-day study of TZP-102 a ghrelin receptor agonist for diabetic gastroparesis. Neurogastroenterol Motil 2013;25:e140e150.

15. McCallum RW, Lembo A, Esfandyari T, et al. Phase 2b, randomized, double-blind 12-week studies of TZP-102, a ghrelin receptor agonist for diabetic gastroparesis. Neurogastroenterol Motil 2013;25:e705-e717.

16. Shin A, Camilleri M, Busciglio I, et al. Randomized controlled phase Ib study of ghrelin agonist, RM-131, in type 2 diabetic women with delayed gastric emptying: pharmacokinetics and pharmacodynamics. Diabetes Care 2013;36:41-48.

17. Lembo A, Camilleri M, McCallum R, et al. Relamorelin reduces vomiting frequency and severity and accelerates gastric emptying in adults with diabetic gastroparesis. Gastroenterology 2016;151:87-96.

18. Camilleri M, McCallum RW, Tack J, Spence SC, Gottesdiener K, Fiedorek FT. Efficacy and safety of relamorelin in diabetics with symptoms of gastroparesis: a randomized, placebo-controlled study. Gastroenterology 2017;153:1240-1250.

19. Liberati A, Altman DG, Tetzlaff J, et al. The PRISMA statement for reporting systematic reviews and meta-analyses of studies that evaluate healthcare interventions: explanation and elaboration. BMJ 2009;339:b2700.

20. Higgins JP, Altman DG, Gøtzsche PC, et al. The Cochrane
Collaboration's tool for assessing risk of bias in randomised trials. BMJ 2011;343:d5928.

21. Revicki DA, Rentz AM, Dubois D, et al. Gastroparesis Cardinal Symptom Index (GCSI): development and validation of a patient reported assessment of severity of gastroparesis symptoms. Qual Life Res 2004;13:833-844.

22. Rentz AM, Kahrilas P, Stanghellini V, et al. Development and psychometric evaluation of the Patient Assessment of Upper Gastrointestinal Symptom Severity Index (PAGI-SYM) in patients with upper gastrointestinal disorders. Qual Life Res 2004;13:17371749.

23. Revicki DA, Camilleri M, Kuo B, Szarka LA, McCormack J, Parkman HP. Evaluating symptom outcomes in gastroparesis clinical trials: validity and responsiveness of the Gastroparesis Cardinal Symptom Index-Daily Diary (GCSI-DD). Neurogastroenterol Motil 2012;24:456-463.

24. Shin A, Camilleri M, Busciglio I, et al. The ghrelin agonist RM-131 accelerates gastric emptying of solids and reduces symptoms in patients with type 1 diabetes mellitus. Clin Gastroenterol Hepatol 2013;11:1453-1459.

25. Janssen P, Harris MS, Jones M, et al. The relation between symptom improvement and gastric emptying in the treatment of diabetic and idiopathic gastroparesis. Am J Gastroenterol 2013;108:1382-1391.

26. Kumar A, Attaluri A, Hashmi S, Schulze KS, Rao SS. Visceral hypersensitivity and impaired accommodation in refractory diabetic gastroparesis. Neurogastroenterol Motil 2008;20:635-642.

27. Tack J, Bisschops R, Sarnelli G. Pathophysiology and treatment of functional dyspepsia. Gastroenterology 2004;127:1239-1255.

28. Khayyam U, Sachdeva P, Gomez J, et al. Assessment of symptoms during gastric emptying scintigraphy to correlate symptoms to delayed gastric emptying. Neurogastroenterol Motil 2010;22:539545.

29. Enck P, Azpiroz F, Boeckxstaens G, et al. Functional dyspepsia. Nat Rev Dis Primers 2017;3:17081.

30. Tack J, Van den Houte K, Carbone F. Gastroduodenal motility disorders. Curr Opin Gastroenterol 2018;34:428-435.

31. Ang D, Nicolai H, Vos R, et al. Influence of ghrelin on the gastric accommodation reflex and on meal-induced satiety in man. Neurogastroenterol Motil 2009;21:528-533.

32. Mao Y, Li Z, Chen K, et al. Antinociceptive effect of ghrelin in a rat model of irritable bowel syndrome involves TRPV1/Opioid systems. Cell Physiol Biochem 2017;43:518-530.

33. Iovino P, Bucci C, Tremolaterra F, Santonicola A, Chiarioni G. Bloating and functional gastro-intestinal disorders: where are we and where are we going? World J Gastroenterol 2014;20:1440714419.

34. Murray CD, Martin NM, Patterson M, et al. Ghrelin enhances gastric emptying in diabetic gastroparesis: a double blind, placebo controlled, crossover study. Gut 2005;54:1693-1698.

35. Ejskjaer N, Vestergaard ET, Hellström PM, et al. Ghrelin receptor agonist (TZP-101) accelerates gastric emptying in adults with 
600 Gut and Liver, Vol. 14, No. 5, September 2020

diabetes and symptomatic gastroparesis. Aliment Pharmacol Ther 2009;29:1179-1187.

36. Wo JM, Ejskjaer N, Hellström PM, et al. Randomised clinical trial: ghrelin agonist TZP-101 relieves gastroparesis associated with severe nausea and vomiting--randomised clinical study subset data. Aliment Pharmacol Ther 2011;33:679-688.
37. Swerdlow AJ, Cooke R, Beckers D, et al. Cancer risks in patients treated with growth hormone in childhood: the SAGhE European Cohort Study. J Clin Endocrinol Metab 2017;102:1661-1672.

38. Sever S, White DL, Garcia JM. Is there an effect of ghrelin/ghrelin analogs on cancer? A systematic review. Endocr Relat Cancer 2016;23:R393-R409. 